\title{
Detoxification enzymes associated with insecticide resistance in laboratory strains of Anopheles arabiensis of different geographic origin
}

\author{
Luisa Nardini ${ }^{1,2^{*}}$, Riann N Christian ${ }^{1,2}$, Nanette Coetzer ${ }^{3}$, Hilary Ranson ${ }^{4}$, Maureen Coetzee ${ }^{1,2}$ and
} Lizette L Koekemoer ${ }^{1,2}$

\begin{abstract}
Background: The use of insecticides to control malaria vectors is essential to reduce the prevalence of malaria and as a result, the development of insecticide resistance in vector populations is of major concern. Anopheles arabiensis is one of the main African malaria vectors and insecticide resistance in this species has been reported in a number of countries. The aim of this study was to investigate the detoxification enzymes that are involved in An. arabiensis resistance to DDT and pyrethroids.

Methods: The detoxification enzyme profiles were compared between two DDT selected, insecticide resistant strains of An. arabiensis, one from South Africa and one from Sudan, using the An. gambiae detoxification chip, a boutique microarray based on the major classes of enzymes associated with metabolism and detoxification of insecticides. Synergist assays were performed in order to clarify the roles of over-transcribed detoxification genes in the observed resistance phenotypes. In addition, the presence of kdr mutations in the colonies under investigation was determined.

Results: The microarray data identifies several genes over-transcribed in the insecticide selected South African strain, while in the Sudanese population, only one gene, CYP9L1, was found to be over-transcribed. The outcome of the synergist experiments indicate that the over-transcription of detoxification enzymes is linked to deltamethrin resistance, while DDT and permethrin resistance are mainly associated with the presence of the L1014F $k d r$ mutation.

Conclusions: These data emphasise the complexity associated with resistance phenotypes and suggest that specific insecticide resistance mechanisms cannot be extrapolated to different vector populations of the same species.
\end{abstract}

Keywords: Anopheles arabiensis, Insecticide resistance, Microarrays, Detoxification enzymes, kdr

\section{Background}

In 2009, the World Health Organization (WHO) estimated 225 million cases of malaria worldwide [1]. Of these, 800000 cases resulted in death, and most of these deaths occurred in Africa where infants, young children and pregnant women were, and still are, worst affected

\footnotetext{
* Correspondence: luisan@nicd.ac.za

${ }^{1}$ Vector Control Reference Unit, Centre for Opportunistic, Tropical and Hospital Infections, National Institute for Communicable Diseases of the National Health Laboratory Services, Private Bag X4, Sandringham, 2131 Johannesburg, South Africa

${ }^{2}$ Malaria Entomology Research Unit, School of Pathology, Faculty of Health Sciences, University of the Witwatersrand, Johannesburg, South Africa
} Full list of author information is available at the end of the article
[1]. Insecticide use has been the most successful way of controlling malaria vectors, and as such, controlling the disease. As a result, the development of insecticide resistance in vector populations has had a major impact on malaria transmission and control.

Anopheles arabiensis is one of the major African malaria vectors and belongs to the An. gambiae complex. Resistance in this species has been reported in a number of countries and to a range of insecticides. Examples include dichlorodiphenyltrichloroethane (DDT), deltamethrin and permethrin resistance in Ethiopia [2,3]; partial resistance to permethrin in Tanzania [4]; DDT, permethrin, malathion and bendiocarb resistance in Sudan [5,6];

\section{Biomed Central}


DDT and permethrin resistance in South Africa [7,8]; and resistance to propoxur in Mozambique [9].

Insecticide resistance is either based on an increase in levels of detoxification enzymes [10], or is related to reduced target-site sensitivity $[10,11]$. Detoxification enzymes that are associated with insecticide resistance belong to large enzyme families, known as super-families. In An. gambiae there are multiple cytochrome P450s $(\mathrm{n}=111)$ [12-16], esterases $(\mathrm{n}=51)$ [14,15,17] and 31 glutathione S-transferase (GSTs) genes $[14,15,17]$. Numerous genes form part of these families and for this reason, it is difficult to determine the specific gene(s) associated with resistance to a particular insecticide, or class of insecticides. The development of high throughput technology such as microarrays provided a solution to this problem [18]. The An. gambiae detoxification microarray is a custom-made boutique array that includes GSTs, esterases and P450s as well as number of redox genes that are associated with P450 metabolism and which protect against free radical damage [19].

In addition to detoxification enzyme mediated protection against insecticides, a number of target-site resistance mechanisms are known. One of the best studied mechanisms in An. gambiae is ' $k d r$ ' or knockdown resistance. This mechanism is characterized by a mutation in the voltage gated sodium channel that confers resistance to both DDT and pyrethroids [2,20-25]. However, the relationship between $k d r$ and cross resistance between insecticide classes is not as clear cut as previously assumed [26]. In An. gambiae for example, the presence of $k d r$ is most strongly correlated with DDT resistance, followed by permethrin resistance, while the weakest association is with the deltamethrin resistant phenotype [27].

In the original study in which the 'detox chip' was presented, the expression profile of detoxification genes associated with DDT resistance in a laboratory colony of An. gambiae was determined [19]. Genes that were overtranscribed included GSTE2, a gene that has previously been linked to DDT resistance [28,29], as well as CYP6Z1, PX13A, PX13B and CYP12F1. Since then, the detox chip has been used in several other studies. More recently, permethrin resistance in a wild An. gambiae population was monitored using the detox chip [30]. Three P450s showed high expression levels: CYP6P3, CYP4H24 and CYP4H19. Although the detox chip was constructed using An. gambiae sequence information, it has been used with success in a number of cross-species hybridizations with An. arabiensis [31], An. funestus [32] and An. stephensi [33].

The aim of this study was to compare the transcription of detoxification enzymes of two laboratory strains of insecticide-resistant $A n$. arabiensis. The colonies were originally derived from different geographic locations, one from Sudan and the other from South Africa. In Sudan, vector control includes the use of long lasting insecticide-treated bed nets (LLINs), temephos for larviciding, and bendiocarb is used for IRS [34]. South African vector control approaches include the use of IRS with DDT in traditional unplastered mud, grass or wooden houses and pyrethroids on walls with enamel painted surfaces $[35,36]$.

\section{Methods}

\section{Mosquito colonies}

Mosquitoes were maintained under standard insectary conditions of $26 \pm 2^{\circ} \mathrm{C}$, a relative humidity of $70-80 \%$, with a 12:12 light:dark cycle and 45 minute dusk/dawn period. The strains used for this study were as follows: An. arabiensis, colonized in the 1980's from the Sennar region of Sudan (SENN) and An. arabiensis, colonized in 2002 from the KwaZulu-Natal (KZN) province in South Africa (MBN). For each colony, both a susceptible or "unselected" strain (called the "base colony") was available, as well as a DDT-resistant strain. The resistant strains have been under continuous DDT selection from the time of colonization. To maintain resistance in the selected colonies, three day old adults were exposed to $4 \%$ DDT in every generation using World Health Organization (WHO) insecticide tubes and procedures [37]. Both DDT selected strains from Sudan and South Africa showed very low or no mortality (after $24 \mathrm{hr}$ recovery period), following exposure to DDT for $1 \mathrm{hr}$ and both were homozygous for the L1014F $k d r$ mutation, as confirmed by PCR using AGD1 and AGD2 primers [23], and sequencing in both directions (data not shown). All strains are maintained in separate insectary rooms to minimise the chance of contamination between strains.

\section{World Health Organization insecticide susceptibility assays}

The insecticide resistance status of the colonies were evaluated against a range of insecticides including DDT (4.0\%), permethrin $(0.75 \%)$, deltamethrin $(0.05 \%)$, bendiocarb $(0.1 \%)$, propoxur $(0.1 \%)$ and fenitrothion $(1.0 \%)$. The assays were done in order to confirm the resistance status of each strain. Assays were performed according to standard WHO procedures [37].

\section{Synergist assays}

Piperonyl butoxide (PBO), an inhibitor of monooxygenase activity, and diethyl maleate (DEM), an inhibitor of GSTs, were used to synergise the resistant colonies, SENN-DDT and MBN-DDT. Twenty-five 2 to 3 day old mosquitoes were exposed to 4.0\% PBO (SENN-DDT and MBN-DDT) or $8.0 \%$ DEM (MBN-DDT) for an hour, and then immediately exposed to insecticide $(0.05 \%$ permethrin, $0.75 \%$ deltamethrin or $4 \%$ DDT) for an hour 
before being returned to a holding tube. In addition, mosquitoes $(\mathrm{n} \approx 25)$ were exposed to the insecticide only (deltamethrin, permethrin or DDT) for an hour, and then as an additional control, to the synergist only (PBO or DEM) for an hour, and were then returned to holding tubes. Mortality was recorded after 24 hours. Insecticide exposure versus synergist plus insecticide exposure were analysed using a $t$-test. Three to four repeats were prepared for each insecticide/synergist assay, depending on mosquito availability.

\section{RNA extractions and CDNA synthesis for microarrays}

Female mosquitoes from the different colonies (SENNbase [susceptible]; SENN-DDT [resistant]; MBN-base [susceptible]; MBN-DDT [resistant]) were collected on the day of emergence and maintained on $10 \%$ sugar water. Three days later, RNA was extracted from 15 mosquitoes, representing one biological repeat. A total of three biological repeats were used in the experiment and analysis described below. RNA was extracted as described by Christian et al. [32].

\section{Microarrays}

Three independent biological repeats were performed for each colony group (SENN and MBN), and for each biological repeat, two technical repeats were performed that included dye swaps in order to compensate for dye bias. Preparation of the probes and microarrays was based on the protocol of Christian et al. [32], with some minor modifications based on the outcome of preliminary experiments. Briefly, amplified antisense (a) RNA was labeled by reverse transcription using Cy-dUTPs. aRNA $(8 \mu \mathrm{g})$ was mixed with random hexamers (Invitrogen), $2 \mu \mathrm{l}$ spike in control (Lucidea Universal ScoreCard, Amersham) and water and the mixture was incubated at $70^{\circ} \mathrm{C}$ for 5 minutes. The reverse transcription mix (RT Buffer, DTT, Cy3-dUTP or Cy5-dUTP, DTT, dT-NTP mix, RNAsin and Superscript ${ }^{\circledR}$ III [Invitrogen]) was added to each RNA and primer mix, and incubated at $50^{\circ} \mathrm{C}$ for 2.5 hours. The reaction was stopped by adding $1 \mathrm{M} \mathrm{NaOH} / 20 \mathrm{mM}$ EDTA, and incubation at $70^{\circ} \mathrm{C}$ for 5 minutes. The $\mathrm{Cy}$-labeled cDNAs were purified using the CyScribe ${ }^{\mathrm{mu}}$ GFX $^{\mathrm{mu}}$ Purification Kit (Amersham) according to manufacturer's instructions. In order to control the efficiency of the labeling and purification procedures, samples were measured on a NanoDrop using the microarray setting. Acceptable dye binding was considered to be $>0.1 \mathrm{pmol} / \mu \mathrm{l}$ and acceptable cDNA yields were required to be $>15 \mathrm{ng} / \mu \mathrm{l}$. If these conditions were not met, the hybridization process was abandoned. Poly(A) was added to each cDNA mix and samples were evaporated at $37^{\circ} \mathrm{C}$ for an hour using an Eppendorf concentrator 5350. The cDNA was resuspended in $15.5 \mu$ l hybridization buffer (Corning) and kept in the dark until slides were ready.
During this time, the microarrays were prepared for hybridization. The Pronto! ${ }^{\text {Im }}$ Universal Microarray Hybridization Kit (Corning) was used, but a 1.5x preparation of each wash solution was used, along with slightly reduced exposure times, following a series of optimization experiments. Once slides were prepared, the labeled targets were denatured by hybridization at $95^{\circ} \mathrm{C}$ for 5 minutes. The targets were added to each array and hybridizations were performed at $42^{\circ} \mathrm{C}$ for $18-20$ hours. After incubation, slides were washed using the Pronto! ${ }^{\mathrm{Tw}}$ Universal Hybridization Kit (1.5x solutions prepared), and dried by centrifugation at $2500 \mathrm{x} g$ for 2 minutes.

\section{Microarray scanning and data analysis}

Analyses were based on those used by Christian et al. [32]. The arrays were scanned using the Genepix 4000B scanner (Molecular Devices, USA) where the PMT values were adjusted to give a pixel ratio of approximately 1 . Spot quality and background intensities were examined and corrected using Genepix Pro 6.0 software (Axon Instruments, USA). Saturated features were recorded as such, and were excluded from analysis.

Gene expression data were analaysed using Limma version 2.12.0 (Bioconductor) [38] in $\mathrm{R}$, version 2.8.0 (http://cran.r-project.org/bin/windows/base/old/2.8.0/), a command-driven program for statistical computing. Raw intensity values for each spot were calculated, and then background corrected by the method "normexp" with an offset of 50. This approach produces positive adjusted intensities and variation in log-ratios for low intensity spots are pushed toward zero (i.e. no spots are "lost" if a high background signal is measured). The corrected intensity values were transformed to log-ratios and then normalized. Control spots were used for within array normalization (i.e. normalization was based on non-differentially expressed control spots). Between array normalization was done using the "Aquantile" method where spot intensity values are transformed so that their distributions are similar between microarrays. MA-plots were viewed so that normalization could be monitored. Once analyses are complete, Limma produces a "topTable", a summary that includes the following: the gene ID, $\mathrm{M}$ ( $\log _{2}$-fold change) and $\mathrm{A}$ ( $\log _{2}$-average intensity) values, a moderated $t$ statistic, a $p$-value, an adjusted $p$-value, a B-statistic as well as an F-statistic (from the 'eBayes' function). Of interest to us were genes with adjusted p-values $\leq 0.05$ and fold-changes $\geq 1.5$. Genes in this category were considered to be statistically significant. These data have been deposited into Vectorbase (https://www.vectorbase.org).

\section{Quantitative real-time PCR (qPCR)}

Real-time PCR was carried out in order to validate the results of the microarray experiments. As with the microarray experiment, RNA was extracted from three 
day old $A n$. arabiensis females that had been supplied with $10 \%$ sugar solution. RNA was extracted from 15 mosquitoes (one biological repeat) using the TRIReagent ${ }^{\circledR}$ Solution (Sigma-Aldrich) and supplied methodology. A DNase treatment was included (RNase-Free DNase Set, Qiagen). Samples were quantified using a NanoDrop and then reverse transcribed into cDNA using the QuantiTect ${ }^{\circledR}$ Reverse Transcription Kit (Qiagen).

cDNA was stored at $-20^{\circ} \mathrm{C}$ until required for PCR. For the SENN colony group, three genes were evaluated by real-time PCR (CYP9L1 [over-transcribed], CO1 [saturated] and CYP4G16 [saturated]), and for the $M B N$ group, four genes were evaluated (CYP6P3, CYP6AK1, CYP6M2 and TPX4, all found to be over-transcribed in the microarray study). Primers were designed based on An. gambiae sequence information using either Beacon Designer $^{\text {TM }}$ (Premier Biosoft) or Invitrogen's free online primer design tool, OligoPerfect ${ }^{\mathrm{TM}}$ Designer. For each colony, a reference gene evaluation was conducted and the most suitable reference gene was selected from all potential candidate genes tested (ribosomal protein S7, ribosomal protein L19 [RPL19], the cytoskeletal protein $\beta$-actin, GAPDH and TATA binding protein). The data from these experiments were analysed using NormFinder (2004, Molecular Diagnostic Laboratory, Aarhus University Hospital). For the SENN colony group, gene expression was measured relative to $r s p 7$, and for the MBN colony group, gene expression was measured against $\beta$-actin. PCR was carried out using the Bio-Rad CFX96 ${ }^{\text {m }}$ Real-Time PCR Detection System. Each reaction was set up using a total volume of $25 \mu \mathrm{l}$ comprising $12.5 \mu \mathrm{l} \mathrm{IQ}{ }^{\text {ts }}$ SYBR super-mix (Bio-Rad), $4 \mu \mathrm{l}$ primer (concentration optimised for each gene), $1 \mu \mathrm{l}$ cDNA $(100 \mathrm{ng} / \mu \mathrm{l})$ and nuclease free water. Primer specifics, including annealing conditions and primer concentrations are described in Table 1 (SENN) and Table 2 $(\mathrm{MBN})$. Standard curves were prepared by two-fold dilutions of cDNA derived from the resistant colony. Three biological repeats were evaluated, and for each biological repeat, three technical repeats were included for each reaction of interest i.e. where relative quantification was calculated. Data were analysed using the Pfaffl [39] method. Initially, PCR product for each gene of interest was sent to Macrogen for sequencing in both directions in order to confirm (over and above melt curve analysis) that the correct product was amplified in each case.

\section{Results}

WHO insecticide susceptibility assays

SENN-base (Table 3) was found to be resistant to permethrin (53\% mortality), but susceptible to all other insecticides tested. SENN-DDT (Table 3) was resistant to DDT, propoxur, permethrin and deltamethrin, and
Table 1 SENN-base/SENN-DDT primer information for qPCR ( $F=$ forward, $R=$ reverse)

\begin{tabular}{|c|c|c|c|}
\hline Gene & Primer sequence & $\begin{array}{l}\text { Annealing } \\
\text { temperature }\end{array}$ & $\begin{array}{l}\text { Amplicon } \\
\text { length }\end{array}$ \\
\hline \multirow[t]{2}{*}{$\overline{C Y P L 9 L 1}$} & $\begin{array}{l}\text { F 5'- AGA TAA TGT ATT } \\
\text { CTT TCG CTA TGG -3' }\end{array}$ & $58.3^{\circ} \mathrm{C}$ & 188 \\
\hline & $\begin{array}{l}\text { R 5'- GCT CTT CTC GCT } \\
\text { CTT GAA C - -3' }\end{array}$ & & \\
\hline \multirow[t]{2}{*}{$\mathrm{CO} 1$} & $\begin{array}{l}\text { F 5'- TGC TCC TAA AAT } \\
\text { AGA AGA AAT TCC -3' }\end{array}$ & $58.3^{\circ} \mathrm{C}$ & 173 \\
\hline & $\begin{array}{l}\text { R 5'- TGC TTC CTC CTT } \\
\text { CAT TAA CAC -3' }\end{array}$ & & \\
\hline \multirow[t]{2}{*}{ CYP4G16 } & $\begin{array}{l}\text { F 5'- CAG ACC GTC CAG } \\
\text { CCA CAT TC - } 3^{\prime}\end{array}$ & $58.3^{\circ} \mathrm{C}$ & 108 \\
\hline & $\begin{array}{l}\text { R 5'-GCG AAC GAG CAA } \\
\text { TTA TAG GTA CTG -3' }\end{array}$ & & \\
\hline \multirow[t]{2}{*}{ rsp 7} & $\begin{array}{l}\text { F 5'-TTA CTG CTG TGT } \\
\text { ACG ATG CC-3' }\end{array}$ & $58.3^{\circ} \mathrm{C}$ & 135 \\
\hline & $\begin{array}{l}\text { R 5'-GAT GGT GGT CTG } \\
\text { CTG GTT-3' }\end{array}$ & & \\
\hline
\end{tabular}

susceptible to bendiocarb and fenitrothion. MBN-base was susceptible to all insecticides tested, while MBNDDT was resistant to all insecticides except fenitrothion (Table 3).

\section{Microarrays and qPCR}

The An. gambiae detox microarray was used in a crossspecies hybridization study with $A n$. arabiensis. As a result, a subset of arrays used for analysis were checked

Table 2 MBN-base/MBN-DDT primer information for qPCR ( $F=$ forward, $R=$ reverse)

\begin{tabular}{|c|c|c|c|}
\hline Gene & Primer sequence & $\begin{array}{l}\text { Annealing } \\
\text { temperature }\end{array}$ & $\begin{array}{l}\text { Amplicon } \\
\text { length }\end{array}$ \\
\hline \multirow[t]{2}{*}{ CYPGM2 } & $\begin{array}{l}\text { F 5'- CAT GAC ACA } \\
\text { AAC CGA CAA GG -3' }\end{array}$ & $60.0^{\circ} \mathrm{C}$ & 235 \\
\hline & $\begin{array}{l}\text { R 5'- GGT GAG GAG } \\
\text { AGT CGA CGA AG -3' }\end{array}$ & & \\
\hline \multirow[t]{2}{*}{ CYPGAK1 } & $\begin{array}{l}\text { F 5'- TCA TCG AGC } \\
\text { GAC AGT GTA CC -3' }\end{array}$ & $58.3^{\circ} \mathrm{C}$ & 251 \\
\hline & $\begin{array}{l}\text { R 5'- AAA GTG TGA } \\
\text { CCC CAG ACA GG -3' }\end{array}$ & & \\
\hline \multirow[t]{2}{*}{ СУР6Р3 } & $\begin{array}{l}\text { F 5'- CGA TTC TTC } \\
\text { CTG GAC ATC GT -3' }\end{array}$ & $58.3^{\circ} \mathrm{C}$ & 141 \\
\hline & $\begin{array}{l}\text { R 5'- CTT GCC CAA } \\
\text { ACT ACC GTC AT -3' }\end{array}$ & & \\
\hline \multirow[t]{2}{*}{ TPX4 } & $\begin{array}{l}F 5^{\prime}-\text { CAG CTG ACA } \\
\text { GAC CGA TTA AG -3' }\end{array}$ & $58.3^{\circ} \mathrm{C}$ & 116 \\
\hline & $\begin{array}{l}\text { R 5'- CCG TTC GGG } \\
\text { AAC AGT TTG TCT -3' }\end{array}$ & & \\
\hline \multirow[t]{2}{*}{$\beta$-actin } & $\begin{array}{l}F 5^{\prime}-\text { ACC AAG AGC } \\
C T G \text { AAG CAC - } 3^{\prime}\end{array}$ & * & 123 \\
\hline & $\begin{array}{l}\text { R 5'- CGA GCA CGA } \\
\text { CAC ACT ATA TAC - -3' }\end{array}$ & & \\
\hline
\end{tabular}

* Annealing temperature used was the same as the target gene of interest. 
Table 3 Mortality data obtained following exposure of (A) SENN-base and SENN-DDT and (B) MBN-base and MBN-DDT to a range of insecticides, all of which belong to classes currently approved by WHO for use in vector control ( $n=$ number of mosquitoes exposed to insecticide)

\begin{tabular}{|c|c|c|c|c|c|c|c|c|}
\hline \multirow[t]{2}{*}{ Insecticide } & \multicolumn{2}{|c|}{ SENN-base } & \multicolumn{2}{|c|}{ SENN-DDT } & \multicolumn{2}{|c|}{ MBN-Base } & \multicolumn{2}{|c|}{ MBN-DDT } \\
\hline & $n$ & $\%$ mortality & $n$ & $\%$ mortality & $n$ & $\%$ mortality & $n$ & $\%$ mortality \\
\hline DDT (4.0\%) & 100 & 100 & 99 & 7.8 & 88 & 91.5 & 96 & 0 \\
\hline Permethrin (0.75\%) & 112 & 53.3 & 99 & 7.0 & 89 & 97.8 & 93 & 4 \\
\hline Deltamethrin (0.05\%) & 106 & 99.0 & 94 & 50.5 & 92 & 100 & 103 & 34 \\
\hline Bendiocarb (0.1\%) & 107 & 97.8 & 97 & 100 & 95 & 95.8 & 102 & 77.5 \\
\hline Propoxur (0.1\%) & 89 & 100 & 112 & 85.5 & 77 & 100 & 95 & 65.3 \\
\hline Fenitrothion (1.0\%) & 105 & 100 & 106 & 100 & 94 & 100 & 71 & 100 \\
\hline
\end{tabular}

for probe binding success, (this was a visual assessment) and where probes did not hybridize, the probe name, and its position on the array were recorded. On average, $97.5 \%$ binding success rate was obtained in this study.

Genes that produced a fold change of $\geq 1.5$ and an adjusted $p$-value of $\leq 0.05$ after microarray analysis were considered to be differentially regulated. When SENNDDT was compared with the relevant base colony in the microarray study, only one gene, CYP9L1, was found to be significantly over-transcribed (Figure 1). In the unselected equivalent, a single gene, CYP6Z1, was overtranscribed. In contrast, in the MBN-DDT colony 20 genes were significantly over-transcribed (Figure 2). Of these, the majority were P450 genes (50\%), followed by GSTs $(40 \%)$ and a small number or redox genes (one TPX and one SOD) (Table 4). Five genes consistently produced saturation on both SENN and MBN microarrays. These were CYP4G16, CO1, GSTD5, SOD3A and $A G M 1$. The transcription of two of these genes was investigated further by real-time PCR. These genes were assessed using the colonies from Sudan.

Relative quantification was used to validate the microarray data. The expression level of CYP9L1 in the Sudanese colony, had a fold change (FC) of 1.7 after

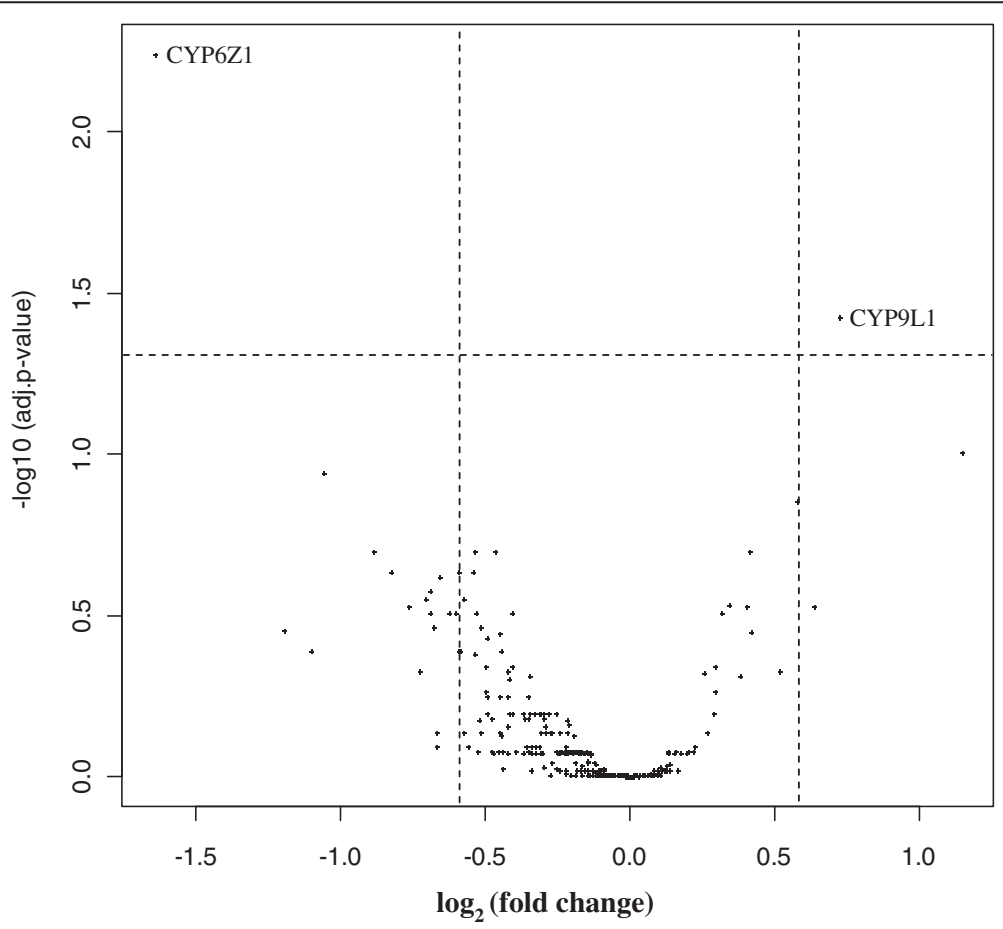

Figure 1 The volcano plot of SENN-base and SENN-DDT microarray data. The plot represents both statistical relevance, in the form of the $p$-value on the $y$-axis, and biological relevance in the form of the fold change on the $x$-axis. The cut-offs for significance are shown (adj. $p$-value $\leq 0.05 ; F C \geq 1.5$ ) and those genes that meet the criteria are labeled. Note that all positive fold change (FC) values represent genes over-transcribed in the resistant colony (SENN-DDT), while negative FC values represent the genes over transcribed in the susceptible colony (SENN-base). 


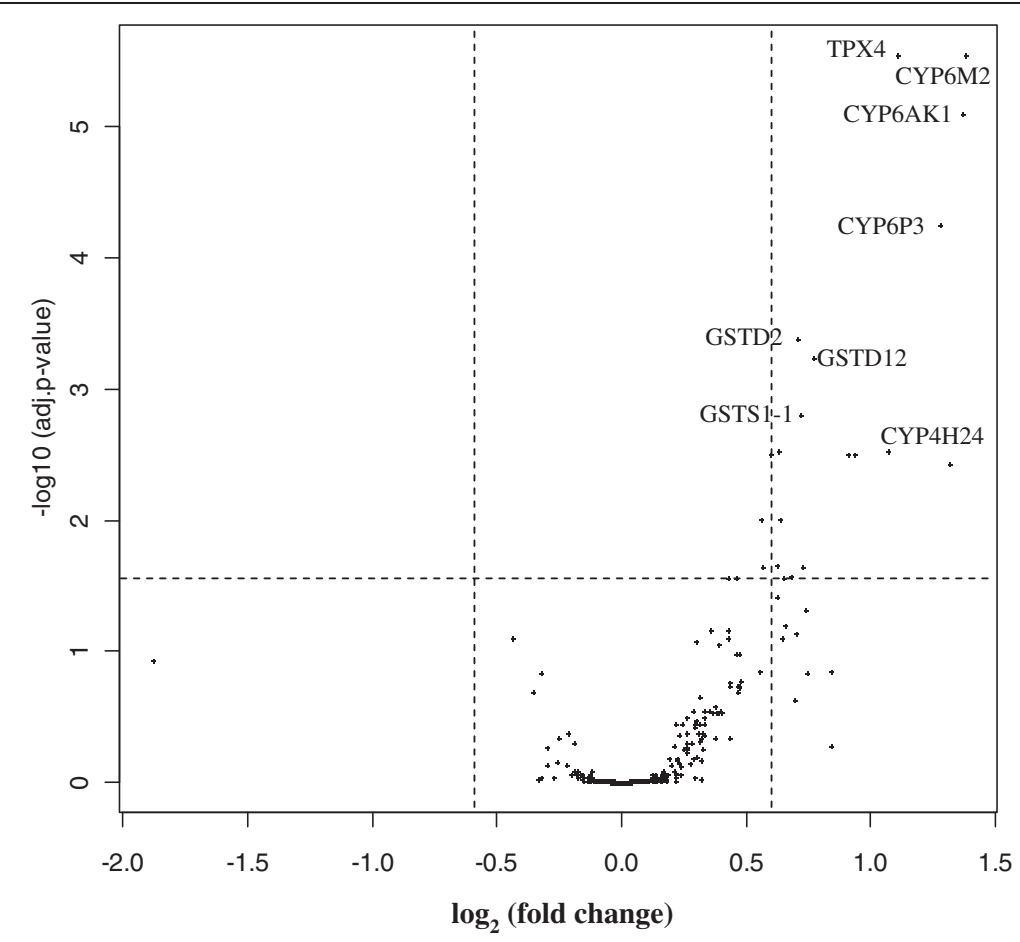

Figure 2 The volcano plot of MBN-base and MBN-DDT microarray data. The plot represents both statistical relevance, in the form of the $p$-value on the $y$-axis, and biological relevance in the form of the fold change on the $x$-axis. The cut-offs for significance are shown (adj. $p$-value $\leq 0.05 ; F C \geq 1.5$ ) and the top eight genes that met the criteria have been labeled. Note that all positive FC values belong to the genes that are over-transcribed in the resistant colony (MBN-DDT), while negative FC values represent those of the susceptible colony (MBN-base).

microarray analysis, and FC of 2.5 after qPCR analysis (Figure 3A). While saturated spots were flagged and not used in analyses, qPCR was also used to measure the FC difference between the susceptible and resistant Sudanese strains. In two of the five genes that were found to be saturated, the cytochrome oxidase, CYP4G16, produced a FC of 1.8 , while $\mathrm{CO1}$, a gene frequently associated with the resistant phenotype, produced a FC of 1.6 (Figure 3A).

In the case of South African An. arabiensis colony (MBN), a sample of four genes that were overtranscribed according to microarary evaluation were validated by qPCR. These genes were the four top genes based on FC and the adjusted $p$-value, namely CYP6M2, TPX4, CYP6AK1 and CYP6P3 (Table 4). The FCs in expression after microarray analyses were comparable to those measured by qPCR. Based on qPCR analysis, CYP6M2 and CYP6P3 each had fold change expression levels of more than 2 while CYP6AK1 and TPX4 produced fold change values of 0.9 and 1.5 respectively (Figure 3B).

\section{Synergist assays}

The synergist assays were used to determine whether the expression of detoxification genes in each colony were in fact related to the resistance observed, or whether the phenotypes were due to the presence of $k d r$. Only one gene (a P450) was over-transcribed in SENNDDT and so only PBO was used as a synergist in this instance. No significant difference in mortality between DDT exposure versus exposure to $\mathrm{PBO}+\mathrm{DDT}$ was found (Table 5). Similarly, no significant difference between permethrin versus $\mathrm{PBO}+$ permethrin was observed. However, the mortality on deltamethrin versus $\mathrm{PBO}+$ deltamethrin was significantly different $(p=0.0006, t=7.7308$, $\mathrm{df}=5$ ) (Table 5). The effects of both DEM and PBO were evaluated in the MBN-DDT colony as monooxygenases and GSTs were over-transcribed in the resistant phenotype according to the microarray experiments. The synergist, $\mathrm{PBO}$, had no significant impact on mosquito response to DDT or permethrin but did impact significantly on MBNDDT response to deltamethrin $(p=0.0004, t=8.331, \mathrm{df}=$ 5). While DEM had no significant impact on DDT and permethrin resistance, a significant difference on mosquito response to deltamethrin versus $\mathrm{DEM}+$ deltamethrin $(p=0.0083, t=4.8596, \mathrm{df}=4))($ Table 5) was observed.

\section{Discussion}

Resistance to DDT and pyrethroids is widespread and has hampered malaria control efforts throughout Africa [2-9]. 
Table 4 List of probes that were over-transcribed in SENN-DDT and MBN-DDT when compared with the susceptible equivalent

\begin{tabular}{|c|c|c|c|c|c|}
\hline $\begin{array}{l}\text { Gene } \\
\text { SENN }\end{array}$ & Function & FC & Adj. $p$-value & $\begin{array}{l}\text { GB accession } \\
\text { number }\end{array}$ & Location \\
\hline CYPQL1 & Cytochrome P450 & 1.7 & $3,74 \mathrm{E}-2$ & AF487781 & $3 L$ \\
\hline \multicolumn{6}{|l|}{ MBN } \\
\hline CYP6M2 & Cytochrome P450 monooxygenase & 2.7 & $6.12 \mathrm{E}-6$ & AY193729 & $3 R$ \\
\hline TPX4 & Thioredoxin-dependent peroxidase & 2.3 & $6.12 \mathrm{E}-6$ & AY745235 & $3 L$ \\
\hline CYP6AK1 & Cytochrome P450 monooxygenase & 2.6 & $2.12 \mathrm{E}-5$ & AY745227 & $3 L$ \\
\hline CYP6P3 & Cytochrome P450 monooxygenase & 2.6 & $1.20 \mathrm{E}-4$ & AF487534 & $2 R$ \\
\hline GSTD2 & Glutathione S-transferase & 1.7 & $3.09 \mathrm{E}-4$ & Z71480 & $2 \mathrm{R}$ \\
\hline GSTS1-1 & Glutathione S-transferase & 1.7 & $7.49 \mathrm{E}-4$ & L07880 & $3 L$ \\
\hline GSTD12 & Glutathione S-transferase & 1.7 & $1.44 \mathrm{E}-3$ & AF316638 & $2 \mathrm{R}$ \\
\hline CYP4H24 & Cytochrome P450 monooxygenase & 2.2 & 4.83E-3 & AY062206 & $x$ \\
\hline GSTD3 & Glutathione S-transferase & 2.0 & 4.91E-3 & AF513638 & $2 R$ \\
\hline CYP6AG2 & Cytochrome P450 monooxygenase & 2.0 & $5.24 \mathrm{E}-3$ & AY745224 & $2 \mathrm{R}$ \\
\hline GSTMS3 & Glutathione S-transferase & 1.6 & $5.83 \mathrm{E}-3$ & AY278448 & $3 R$ \\
\hline GSTS1-2 & Glutathione S-transferase & 1.5 & $6.71 \mathrm{E}-3$ & AF513639 & $3 L$ \\
\hline CYP9J5 & Cytochrome P450 monooxygenase & 2.7 & $7.73 \mathrm{E}-3$ & AY748830 & $3 L$ \\
\hline CYP6P1 & Cytochrome P450 monooxygenase & 1.5 & $7.73 \mathrm{E}-3$ & AY028785 & $2 \mathrm{R}$ \\
\hline SOD1 & Superoxide dismutase & 1.6 & 1.13E-2 & AY505417 & $3 L$ \\
\hline СYР6M3 & Cytochrome P450 monooxygenase & 1.8 & $1.58 \mathrm{E}-2$ & AY193730 & $3 R$ \\
\hline GSTU1 & Glutathione S-transferase & 1.6 & $1.58 \mathrm{E}-2$ & AF515521 & $x$ \\
\hline CYP12f2 & Cytochrome P450 & 1.7 & 1.83E-2 & AY176050 & $3 R$ \\
\hline GSTMS1 & Glutathione S-transferase & 1.6 & $3.81 \mathrm{E}-2$ & AY278446 & $x$ \\
\hline CYP12F4 & Cytochrome P450 monooxygenase & 1.7 & 4.01E-2 & AY176048 & $3 R$ \\
\hline
\end{tabular}

Relevant information included is the gene function, FC, adjusted p-value, Genbank (GB) accession number and the chromosomal location of each gene in the An. gambiae genome.

Artificial insecticide resistance selection on laboratory colonies is useful as it allows one to study the resistance mechanism on a population not influenced by other environmental selection pressures. Furthermore, artificial selection in the laboratory allows us to mimic the development of insecticide resistance from repeated and continuous exposure to insecticides, a situation that wild vector populations are frequently exposed to.

The two resistant An. arabiensis colonies used in this study, one from South Africa and the other from Sudan, have been under DDT selection pressure in the laboratory. Bioassay data confirmed that both SENN-DDT and MBN-DDT are highly resistant to DDT. In addition to a high level of DDT resistance, the two colonies were found to be resistant to pyrethroids (deltamethrin and permethrin). The South African population showed additional resistance to carbamates, which was not present in the Sudanese colony.

The development of multiple insecticide resistance in the above mentioned colonies is supported by subsequent studies published on the same laboratory populations. The MBN colony was colonized in 2002 without detecting pyrethroid resistance in the population. However, three years later Mouatcho et al. [8] reported the presence of pyrethroid resistance, which was rapidly selected for (within four generations) in the laboratory and has been shown to be P450 based. The same author also showed that carbamate tolerance could be selected for from the same colonized field population. Ranson et al. [34] recently published a country wide study and showed that An. arabiensis populations from Sudan are resistant to both DDT and pyrethroids, but remained fully susceptible to carbamates and the organophosphate, fenitrothion. This supports what was observed in the SENN-DDT colony.

The fact that DDT and pyrethroid resistance in $A n$. gambiae are linked has been well-documented and has been attributed to the presence of $k d r$ mutations [23,25]. Specifically, $k d r$ is strongly linked with DDT and permethrin resistance, and less so with deltamethrin resistance $[27,40]$. In $A n$. arabiensis, the relationship between the presence of $k d r$ mutations and resistance phenotype 

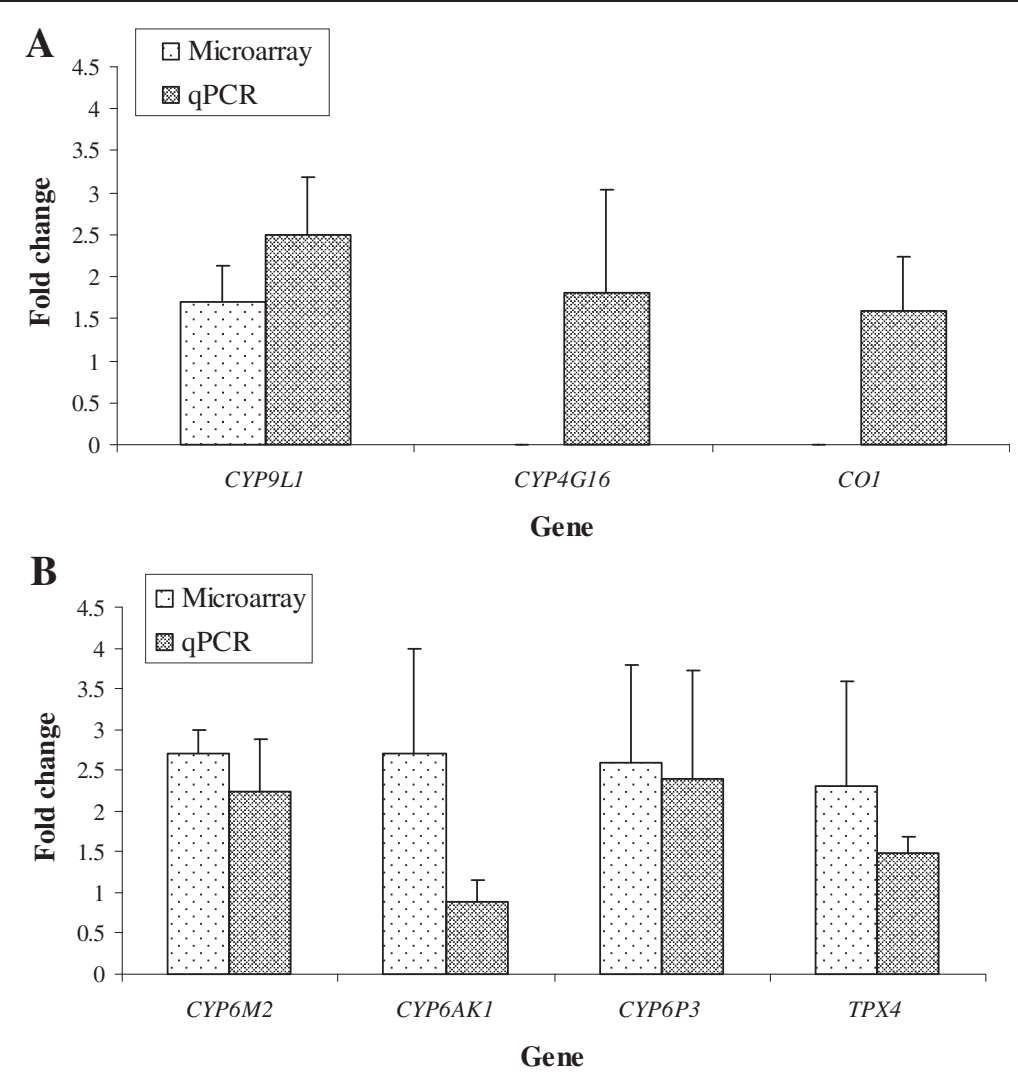

Figure 3 A comparison of the outcome of gene expression evaluation (mean \pm SD) by microarrays and by qPCR in selected genes in (A) the SENN colony group and (B) the MBN colony group. Genes of interest were measured against the relevant reference genes.

is also complicated [2,41]. The SENN-DDT colony is fixed for the L1014F mutation. The South African An. arabiensis population has previously been confirmed not to carry any $k d r$ mutations $[7,8]$. However, the continued selection pressure from exposure of MBN-DDT to DDT has resulted in this colony being fixed for the L1014F mutation. The L1014S mutation is absent from both laboratory colonies.

The detoxification enzyme profiles of the two laboratory selected DDT-resistant An. arabiensis strains was investigated using cross-species hybridizations of An. arabiesnsis genetic material with the An. gambiae detoxification microarray (detox chip). Of the 98\% of probes that hybridized, only one gene in the SENNDDT colony was over-transcribed. This was a cytochrome P450, CYP9L1. This was in contrast to the MBN colony where a similar success rate of probe hybridization was recorded, but 20 genes were highly transcribed in the resistant phenotype.

The use of the An. gambiae detox chip allows for the evaluation of transcription of a large number of genes simultaneously, but the criteria one uses to find significance will determine how many genes are of interest for further study. In other studies (both same- and crossspecies hybridizations) the cut-off for significance in terms of fold change ranged from $>1.5$ to 2.0 , and the $p$-value cut-off for significance ranged form $<0.001$ to $<0.05[32,33,42-44]$. Generally, where a higher foldchange was used as criteria to identify over-transcribed genes, a lower $p$-value cut-off was also used to determine significance, and vice versa. In this study, the stringency was adjusted for the wash solutions by increasing the required amount of each solution (i.e. higher than what was recommended by the supplier). The experimental conditions selected produced the best arrays, but because the experiment was based on cross-species hybridizations, we chose to use less strict criteria for identifying those genes with a significant level of differential transcription.

The action of the P450-dependent monooxygenases is one of the ways in which insects become resistant to insecticides [16]. Only one gene, CYP9L1, showed high expression levels in the SENN resistant phenotype and is likely to play a key role in the observed resistance to deltamethrin. The CYP9 gene family is closely related to the CYP6 family (highly expressed in the MBN resistant 
Table 5 Percentage mortality of SENN-DDT and MBN-DDT mosquitoes (females and males) to DDT and deltamethrin following exposure to synergists ( $n=$ number of mosquitoes tested)

\begin{tabular}{|c|c|c|c|}
\hline Colony & Treatment & $n$ & $\begin{array}{c}\% \text { Mortality } \\
( \pm \text { SD) }\end{array}$ \\
\hline \multirow[t]{9}{*}{ SENN-DDT } & $\mathrm{PBO}(4 \%)+\mathrm{DDT}(4 \%)$ & 107 & $3.9( \pm 4.7)$ \\
\hline & DDT (4\%) only & 107 & $13.0( \pm 8.6)$ \\
\hline & PBO (4\%) only & 80 & 0 \\
\hline & PBO (4\%) + deltamethrin (0.05\%) & 126 & $83.8( \pm 1.3)^{*}$ \\
\hline & Deltamethrin (0.05\%) only & 89 & $25.3( \pm 15.6)^{*}$ \\
\hline & PBO (4\%) only & 80 & 0 \\
\hline & $\mathrm{PBO}(4 \%)+$ permethrin $(0.75 \%)$ & 75 & 0 \\
\hline & Permethrin (0.75\%) only & 72 & $1.3( \pm 2.3)$ \\
\hline & PBO (4\%) only & 79 & $2.7( \pm 4.6)$ \\
\hline \multirow[t]{9}{*}{ MBN-DDT } & $\mathrm{PBO}(4 \%)+\mathrm{DDT}(4 \%)$ & 79 & $2.3( \pm 2.1)$ \\
\hline & DDT (4\%) only & 71 & $1.3( \pm 2.3)$ \\
\hline & PBO (4\%) only & 81 & $1.1( \pm 2.0)$ \\
\hline & PBO (4\%) + deltamethrin (0.05\%) & 78 & $70.3( \pm 16.5)^{*}$ \\
\hline & Deltamethrin (0.05\%) only & 97 & $2.2( \pm 4.3)^{*}$ \\
\hline & PBO (4\%) only & 81 & $1.1( \pm 2.0)$ \\
\hline & PBO (4\%) + permethrin (0.75\%) & 74 & $1.3( \pm 2.3)$ \\
\hline & Permethrin (0.75\%) only & 73 & $6.7( \pm 4.6)$ \\
\hline & PBO (4\%) only & 74 & $1.3( \pm 2.3)$ \\
\hline \multirow[t]{9}{*}{ MBN-DDT } & DEM (7\%) + DDT (4\%) & 80 & $1.5( \pm 2.6)$ \\
\hline & DDT (4\%) only & 72 & $4.0( \pm 4.0)$ \\
\hline & DEM (7\%) only & 82 & $3.5( \pm 3.7)$ \\
\hline & DEM $(7 \%)+$ deltamethrin (0.05\%) & 74 & $46.0( \pm 1.7)^{*}$ \\
\hline & Deltamethrin (0.05\%) only & 78 & $16.8( \pm 10.2)^{*}$ \\
\hline & DEM (7\%) only & 82 & $3.5( \pm 3.7)$ \\
\hline & DEM (7\%) + permethrin (0.75\%) & 75 & $1.7( \pm 2.9)$ \\
\hline & Permethrin (0.75\%) only & 75 & 0 \\
\hline & DEM (7\%) only & 69 & $3.0( \pm 2.7)$ \\
\hline
\end{tabular}

* Indicates significant difference between insecticide versus synergist and insecticide.

phenotype) [45] and members have been linked to insecticide resistance in a number of insects [44-46]. Although not likely to be the case here, it is interesting to note that a single P450 enzyme has been implicated in resistance to DDT $[47,48]$.

Five genes were consistently saturated when both MBN- and SENN-DDT arrays were analysed. Some of these were mainly saturated in one channel, and less so in the other, which raises the possibility that a gene is over-transcribed, but this is masked by the saturation, and might therefore be overlooked. Two of these, CYP4G16 and CO1, were investigated further using qPCR and SENN-DDT genetic material. The monoxygenase, CYP4G16 was chosen because it has previously been linked to pyrethroid tolerance in An. arabiesnis [31]. The cytochrome oxidase gene, CO1, was selected as it was over-transcribed in a microarray study on pyrethroid resistant An. funestus [32]. In this study, we obtained FC values of 1.8 and 1.6 for CYP4G16 and CO1 respectively after $\mathrm{qPCR}$ analysis. While these values are relatively low when compared with previously reported data, their involvement, if any, in resistance and the reason for saturation on the microarrays should be investigated further.

According to our criteria, 20 genes were differentially regulated in the resistant MBN colony and most of these genes belong to the monooxygenase and GST enzyme groups. In addition, most of the over-transcribed CYP genes belonged to the CYP6 family, which is frequently associated with insecticide resistance in insects. The top four genes were selected for $\mathrm{qPCR}$ validation. These were, in order of significance, CYP6M2, TPX4, CYP6AK1 and CYP6P3. Recently, Munhenga and Koekemoer [49] used qPCR to assess the transcription of a range of monooxygenase genes in a pyrethroid-selected $A n$. arabiensis colony from the same geographical area (KZN, South Africa). They found that CYP6Z1 (FC=4.7), CYP6Z2 $(\mathrm{FC}=1.7)$ and CYP6M2 $(\mathrm{FC}=2.2)$ were significantly over-transcribed. Interestingly, in our evaluation of CYP6M2, qPCR produced a FC of 2.2, the same level as that reported by Munhenga and Koekemoer [49], even though a different reference gene was used between the two studies.

Of the CYP genes that were over-transcribed in this study according to microarray evaluation, a number have been implicated in insecticide resistance in An. gambiae. Djouaka et al. [50] found that CYP6P3 and CYP6M2 were both upregulated in pyrethroid-resistant An. gambiae populations in Benin and Southern Nigeria. In permethrin-resistant An. gambiae from Ghana, CYPM2, CYP6AK1 and CYP6P3 were amongst the top 10 differentially expressed genes in resistant mosquitoes [30]. The authors found that the outcomes of the microarray and $\mathrm{qPCR}$ data were similar as was confirmed in the present study.

The GSTs also featured prominently in the enzyme profile of resistant MBN colony. The epsilon class GSTs have been specifically linked to DDT resistance in An. gambiae [29,51-54] and delta class GSTs to a lesser extent [52]. Furthermore, GSTs have more recently been linked to pyrethroid resistance in other insects [55,56] and so their presence in the resistance profile of MBN-DDT might be linked directly to protection against the pyrethroid, deltamethrin. Because they help to protect cells against oxidative stress, their over-expression in the MBN-DDT colony is also likely to be linked to the action of the cytochrome P450s where the GSTs are involved in secondary metabolism through the action of glutathione peroxidase [52]. 
A number of enzymes, namely the SODs, TPXs and GRXs, counteract the effects of reactive oxygen molecules, which are harmful to the host [57]. The SODs function by converting superoxide anions to hydrogen peroxide and oxygen [58]. In turn, the TPXs are involved in the removal of hydrogen peroxide [58]. Based on microarray experiments, we reported high levels of TPX4 (2.3 fold) expression in the South African population of DDT selected $A n$. arabiensis. This enzyme was over-transcribed in An. arabiensis during the spraying season of a cotton field in Cameroon [31], while TPX1 was over-expressed in An. gambiae, resistant to pyrethroids, from Ghana [59]. In the MBN colony, whether the high expression of TPX4 is related directly to the activities of the P450 enzymes (to counteract metabolic byproducts), or is a function of the insecticide resistance selection process where they are on "stand-by" to provide protection against pyrethroids, is unknown.

According to Brooke and Koekemoer [27], and references therein, the correlation between the presence of $k d r$ and mosquito response to insecticide is strongest in the case of DDT, less so with permethrin, and weakest with deltamethrin. The outcome of the synergist studies performed here suggests that detoxification enzymes have no impact on DDT resistance in these strains, but are very important for protection against the pyrethroid, deltamethrin. The presence of the L1014F $k d r$ mutations is likely to assist in protection against permethrin.

\section{Conclusions}

The combination of expression data and synergist data suggests that the systems in place for insecticide resistance are extremely complex. There is a lack of understanding as to how these genes interact and support each other in the detoxification of specific insecticides and further investigation into these molecular mechanisms is needed. It is clear that the metabolic genes associated with each resistant colony are unique for that population and there was no single gene that showed an increase in transcription between South Africa and Sudan. However, a number of genes identified in this study as being over-transcribed have been flagged in other studies for their possible roles in insecticide resistance of An. arabiensis. It would be valuable to replicate this study in wild populations from these regions and compare the results of enzyme studies based on laboratory colonies and wild-caught mosquitoes.

\section{Abbreviations}

WHO: World Health Organization; DDT: Dichlorodiphenyltrichloroethane; GST: Glutathione S-transferase; P450: Cytochrome oxidase/P450;

SOD: Superoxide dismutase; TPX: Thioredoxin peroxidase; kdr: Knockdown resistance; IRS: Indoor residual spraying; LLIN: Long-lasting insecticide treated bednet; KZN: KwaZulu-Natal.

\section{Competing interests}

The authors declare that they have no competing interests.

\section{Acknowledgements}

LN acknowledges the support of the National Research Foundation (NRF) and the Deutscher Akademischer Austausch Dienst. LLK is supported by the NRF and the National Health Laboratory Service Research Trust. MC is supported by the South African Research Chair Initiative of the Department of Science and Technology and the NRF.

\section{Author details}

${ }^{1}$ Vector Control Reference Unit, Centre for Opportunistic, Tropical and Hospital Infections, National Institute for Communicable Diseases of the National Health Laboratory Services, Private Bag X4, Sandringham, 2131 Johannesburg, South Africa. ${ }^{2}$ Malaria Entomology Research Unit, School of Pathology, Faculty of Health Sciences, University of the Witwatersrand, Johannesburg, South Africa. ${ }^{3}$ Bioinformatics and Computational Biology Unit, Department of Biochemistry, University of Pretoria, Pretoria, South Africa. ${ }^{4}$ Vector Research Group, Liverpool School of Tropical Medicine, Liverpool, UK.

\section{Authors' contributions}

LN conducted the experiments and data analyses, interpreted results, and drafted the first version of the manuscript. RC provided technical support for the duration of the study, particularly with regard to the microarrays and $\mathrm{qPCR}$, and contributed to the editing of the manuscript. NC participated in the microarray data analysis and provided useful comments for the manuscript. HR contributed to revision of the manuscript. MC provided funding for the study and contributed to revision of the manuscript. LLK provided funding for the study, conceived the project, participated in coordinating the study and helped with revision of the manuscript. All authors have read and approved the final manuscript.

Received: 2 May 2012 Accepted: 3 June 2012

Published: 7 June 2012

\section{References}

1. World Health Organization: World Malaria Report 2010. Geneva, Switzerland: WHO Press; 2010 http://whqlibdoc.who.int/publications/2010/ 9789241564106_eng.pdf.

2. Balkew M, Ibrahim M, Koekemoer LL, Brooke BD, Engers H, Aseffa A, GebreMichael T, Elhassen I: Insecticide resistance in Anopheles arabiensis (Diptera: Culicidae) from villages in central, northern and south west Ethiopia and detection of kdr mutation. Parasit Vectors 2010, 3:40.

3. Yewhalaw D, Wassie F, Steurbaut W, Spanoghe P, Van Bortel W, Denis L, Tessema DA, Getachew Y, Coosemans M, Duchateau L, Speybroeck N: Multiple insecticide resistance: an impediment to insecticide-based malaria vector control program. PLoS One 2011, 6:e16066.

4. Matowo J, Kulkarni MA, Mosha FW, Oxborough RM, Kitau JA, Tenu F, Rowland M: Biochemical basis of permethrin resistance in Anopheles arabiensis from Lower Moshi, north-eastern Tanzania. Malar. J 2010, 9:193

5. Abdalla H, Matambo TS, Koekemoer LL, Mnzava AP, Hunt RH, Coetzee M: Insecticide susceptibility and vector status of natural populations of Anopheles arabiensis from Sudan. Trans R Soc Trop Med Hyg 2008, 102:263-271.

6. Hemingway J: Biochemical studies on malathion resistance in Anopheles arabiensis from Sudan. Trans R Soc Trop Med Hyg 1983, 77:477-480.

7. Hargreaves K, Hunt RH, Brooke BD, Mthembu J, Weeto MM, Awolola TS, Coetzee M: Anopheles arabiensis and An. quadriannulatus resistance to DDT in South Africa. Med Vet Entomol 2003, 17:417-422.

8. Mouatcho JC, Munhenga G, Hargreaves K, Brooke BD, Coetzee M, Koekemoer LL: Pyrethroid resistance in a major African malaria vector Anopheles arabiensis from Mamfene, northern KwaZulu-Natal, South Africa. S Afr J Sci 2009, 105:127-131.

9. Casimiro S, Coleman M, Hemingway J, Sharp B: Insecticide resistance in Anopheles arabiensis and Anopheles gambiae from Mozambique. J Med Entomol 2006, 43:276-282.

10. Feyereisen R: Molecular biology of insecticide resistance. Toxicol Lett 1995, 82/83:83-90.

11. ffrench-Constant $\mathrm{RH}$ : Target site mediated insecticide resistance: what questions remain? Insect Biochem Mol Biol 1999, 29:397-403. 
12. Bergé J-P, Feyereisen R, Amichot M: Cytochrome P450 monooxygenases and insecticide resistance. In Insecticide resistance: from mechanisms to management. Edited by Denholm I, Pickett JA, Devonshire AL. UK: CABI Publishing; 1999.

13. Feyereisen R: Insect P450 enzymes. Annu Rev Entomol 1999, 44:507-533.

14. Hemingway J, Hawkes NJ, McCarroll L, Ranson H: The molecular basis of insecticide resistance in mosquitoes. Insect Biochem Mol Biol 2004, 34:653-665.

15. Ranson H, Nikou D, Hutchinson M, Wang X, Roth CW, Hemingway J, Collins $\mathrm{FH}$ : Molecular analysis of multiple cytochrome $\mathrm{P} 450$ genes from the malaria vector, Anopheles gambiae. Insect Mol Biol 2002, 11:409-418.

16. Scott JG: Cytochromes P450 and insecticide resistance. Insect Biochem Mol Biol 1999, 29:757-777.

17. Hemingway J: The molecular basis of two contrasting metabolic mechanisms of insecticide resistance. Insect Biochem Mol Biol 2002, 30:1009-1015

18. Naidoo S, Denby KJ, Berger DK: Microarray experiments: considerations for experimental design. S Afr J Sci 2005, 101:347-354.

19. David J-P, Strode C, Vontas J, Nikou D, Vaughan A, Pignatelli PM, Louis C, Hemingway J, Ranson H: The Anopheles gambiae detoxification chip: a highly specific microarray to study metabolic-based insecticide resistance in malaria vectors. Proc Natl Acad Sci USA 2005, 102:4080-4084

20. Awolola TS, Brooke BD, Koekemoer LL, Coetzee M: Absence of the kdr mutation in the molecular ' $\mathrm{M}$ ' form suggests different pyrethroid resistance mechanisms in the malaria mosquito Anopheles gambiae s.s. Trop Med Int Health 2003, 8:420-422.

21. Diabaté $A$, Baldet $T$, Chandre $F$, Akogbeto $M$, Guiguemde TR, Darriet $F$, Brengues C, Guillet P, Hemingway J, Small G, Hougard JM: The role of agricultural use of insecticides in resistance to pyrethroids in Anopheles gambiae s.l. in Burkina Faso. Am J Trop Med Hyg 2002, 67:617-622.

22. Etang J, Fondjo E, Chandre F, Morlais I, Brengues C, Nwane P, Chouaibou M, Ndjemai $\mathrm{H}$, Simard F: Short report: first report of knockdown mutations in the malaria vector Anopheles gambiae from Cameroon. Am J Trop Med Hyg 2006, 74:795-797.

23. Martinez-Torres D, Chandre F, Williamson MS, Darriet F, Bergé JB, Devonshire AL, Guillet P, Pasteur N, Pauron D: Molecular characterization of pyrethroid resistance $(k d r)$ in the major malaria vector Anopheles gambiae s.s. Insect Mol Biol 1998, 7:179-184.

24. Nwane P, Etang J, Chouaibou M, Toto JC, Kerah-Hinzoumbé C, Mimpfoundi $\mathrm{R}$, Awono-Ambene HP, Simard F: Trends in DDT and pyrethroid resistance in Anopheles gambiae s.s. populations from urban and agro-industrial settings in southern Cameroon. BMC Infect Dis 2009, 9:163.

25. Ranson $H$, Jensen B, Vulule JM, Wang $X$, Hemingway J, Collins FH: Identification of a point mutation in the voltage-gated sodium channel gene of Kenyan Anopheles gambiae associated with resistance to DDT and pyrethroids. Insect Mol Biol 2000, 9:491-497.

26. Brooke BD: $k d r$ : can a single mutation produce an entire insecticide resistance phenotype? Trans $R$ Soc Trop Med Hyg 2008, 102:524-525.

27. Brooke BD, Koekemoer LL: Major effects or loose confederations? The development of insecticide resistance in the malaria vector Anopheles gambiae. Parasit Vectors 2010, 3:74.

28. Ortelli F, Rossiter LC, Vontas J, Ranson H, Hemingway J: Heterologous expression of four glutathione transferase genes genetically linked to a major insecticide-resistance locus from the malaria vector Anopheles gambiae. Biochem J 2003, 373:957-963.

29. Ranson H, Rossiter L, Ortelli F, Jensen B, Wang X, Roth CW, Collins FH, Hemingway J: Identification of a novel class of insect glutathione $\mathrm{S}$ transferases involved in resistance to DDT in the malaria vector Anopheles gambiae. Biochem J 2001, 359:295-304.

30. Müller P, Warr E, Stevenson BJ, Pignatelli PM, Morgan JC, Steven A, Yawson AE, Mitchell SN, Ranson H, Hemingway J, Paine MJI, Donnelly MJ: Fieldcaught permethrin-resistant Anopheles gambiae overexpress CYP6P3, a P450 that metabolises pyrethroids. PLoS Genet 2008, 4:e1000286.

31. Müller $P$, Chouaïbou M, Pignatelli $P$, Etang J, Walker ED, Donnelly MJ, Simard $\mathrm{F}$, Ranson $\mathrm{H}$ : Pyrethroid tolerance is associated with elevated expression of antioxidants and agricultural practice in Anopheles arabiensis sampled from an area of cotton fields in Northern Cameroon. Mol Ecol 2007, 17:1145-1155.

32. Christian RN, Strode C, Ranson H, Coetzer N, Coetzee M, Koekemoer LL: Microarray analysis of a pyrethroid resistant African malaria vector, Anopheles funestus, from Southern Africa. Pestic Biochem Physiol 2011, 99:140-147.
33. Vontas J, David J-P, Nikou D, Hemingway J, Christophides GK, Louis C, Ranson $\mathrm{H}$ : Transcriptional analysis of insecticide resistance in Anopheles stephensi using cross-species microarray hybridization. Insect Mol Biol 2007, 16:315-324.

34. Ranson H, Abdallah H, Badolo A, Guelbeogo WM, Kerah-Hinzoumbé C, Yangalbé-Kalnoné E, Sagnon N, Simard F, Coetzee M: Insecticide resistance in Anopheles gambiae: data from the first year of a multi-country study highlight the extent of the problem. Malar J 2009, 8:299.

35. Coleman M, Coleman M, Mabuza AM, Kok G, Coetzee M, Durrheim DN: Evaluation of an operational malaria outbreak identification and response system in Mpumalanga Province. South Africa. Malar J 2008, 7:69.

36. Maharaj R, Mthembu DJ, Sharp B: Impact of DDT re-introduction on malaria transmission in KwaZulu-Natal. S Afr Med J 2005, 95:871-874.

37. World Health Organization: Test procedures for insecticide resistance monitoring in malaria vectors, bio efficacy and persistence of insecticides on treated surfaces. Geneva: WHO; 1998. WHO/CDS/CPC/MAL98.12 http://www. who.int/whopes/resistance/en/

38. Smyth GK: Limma: linear models for microarry data. In Bioinformatics and Computational Biology Solutions using $R$ and Bioconductor. Edited by Gentleman R, Carey V, Dudoit S, Irizarry R, Huber W. New York: Springer; 2005.

39. Pfaffl MW: A new mathematical model for relative quantification in realtime RT-PCR. Nucleic Acids Res 2001, 29:45.

40. Ramphul U, Boase T, Bass C, Okedi LM, Donnelly MJ, Müller P: Insecticide resistance and its association with target-site mutations in natural populations of Anopheles gambiae from eastern Uganda. Trans $R$ Soc Trop Med Hyg 2009, 103:1121-1126.

41. Matambo TS, Abdalla H, Brooke BD, Koekemoer LL, Mnzava A, Hunt RH, Coetzee $\mathrm{M}$ : Insecticide resistance in the malaria mosquito Anopheles arabiensis and association with the kdr mutation. Med Vet Entomol 2007, 21:97-102.

42. Girardot F, Monnier V, Tricoire H: Genome wide analysis of common and specific stress responses in adult Drosophila melanogaster. BMC Genomics 2004, 5:74.

43. Poupardin R, Reynaud S, Strode C, Ranson H, Vontas J, David J-P: Crossinduction of detoxification genes by environmental xenobiotics and insecticides in the mosquito Aedes aegypti: impact on larval tolerance to chemical insecticides. Insect Biochem Mol Biol 2008, 38:540-551.

44. Strode C, Wondji CS, David J-P, Hawkes NJ, Lumjuan N, Nelson DR, Drane DR, Karunaratne SHPP, Hemingway J, Black WC IV, Ranson H: Genomic analysis of detoxification genes in the mosquito Aedes aegypti. Insect Biochem Mol Biol 2007, 38:113-123.

45. Rose RL, Goh D, Thompson DM, Verma JD, Heckel DG, Gahan LJ, Roe RM, Hodgson E: Cytochrome P450 (CYP)9A1 in Heliothis virescens: the first member of a new CYP family. Insect Biochem Mol Biol 1997, 27:605-615.

46. Zhou X, Sheng C, Li M, Wan H, Liu D, Qiu X: Expression responses of nine cytochrome P450 genes to xenobiotics in the cotton bollworm Helicoverpa armigera. Pestic Biochem Physiol 2010, 97:209-213.

47. Daborn PJ, Yen JL, Bogwitz MR, Le Goff G, Feil E, Jeffers S, Tijet N, Perry T, Heckel D, Batterham P, Feyereisen R, Wilson TG, ffrench-Constant RH: A single P450 allele associated with insecticide resistance in Drosophila. Science 2002, 297:2253-2256.

48. Chiu T-L, Wen Z, Rupasinghe SG, Schuler M: Comparative molecular modeling of Anopheles gambiae CYP6Z1, a mosquito P450 capable of metabolizing DDT. Proc Natl Acad Sci USA 2008, 105:8855-8860.

49. Munhenga G, Koekemoer LL: Differential expression of cytochrome P450 genes in a laboratory selected Anopheles arabiensis colony. Afr J Biotech 2011, 10:12711-12716.

50. Djouaka RF, Bakare AA, Coulibaly ON, Akogbeto MC, Ranson H, Hemingway J, Strode C: Expression of the cytochrome P450s, CYP6P3 and CYP6M2 are significantly elevated in multiple pyrethroid resistant populations of Anopheles gambiae s.s. from Southern Benin and Nigeria. BMC Genomics 2008, 9:538.

51. Brown AWA: Insecticide resistance in mosquitoes: a pragmatic review. J Am Mosq Control Assoc 1986, 2:123-140.

52. Che-Mendoza A, Penilla RP, Rodríguez DA: Insecticide resistance and glutathione S-transferases in mosquitoes: a review. Afr J Biotech 2009, 8:1386-1397.

53. Ding Y, Ortelli F, Rossiter LC, Hemingway J, Ranson H: The Anopheles gambiae glutathione transferase supergene family: annotation, phylogeny and expression profiles. BMC Genomics 2003, 4:35. 
54. Ranson H, Prapanthadara L, Hemingway J: Cloning and characterization of two glutathione S-transferases from a DDT-resistant strain of Anopheles gambiae. Biochem J 1997, 324:97-102.

55. Kostaropoulos I, Papadopoulos Al, Metaxakis A, Boukouvala E,

Papadopoulou-Mourkidou E: Glutathione S-transferase in the defence against pyrerthoids in insects. Insect Biochem Mol Biol 1997, 31:313-319.

56. Vontas JG, Small GJ, Hemingway J: Glutathione S-transferases as antioxidant defence agents confer pyrethroid resistance in Nilparvata lugens. Biochem J 2001, 357:65-72.

57. Corona M, Robinson GE: Genes of the antioxidant system of the honey bee: annotation and phylogeny. Insect Mol Biol 2006, 15:687-701.

58. Fridovich I: The biology of oxygen radicals. Science 1978, 201:875-880.

59. Müller P, Donnelly MJ, Ranson H: Transcription profiling of a recently colonized pyrethroid resistant Anopheles gambiae strain from Ghana. BMC Genomics 2007, 8:36.

doi:10.1186/1756-3305-5-113

Cite this article as: Nardini et al.: Detoxification enzymes associated with insecticide resistance in laboratory strains of Anopheles arabiensis of different geographic origin. Parasites \& Vectors 2012 5:113.

\section{Submit your next manuscript to BioMed Central and take full advantage of:}

- Convenient online submission

- Thorough peer review

- No space constraints or color figure charges

- Immediate publication on acceptance

- Inclusion in PubMed, CAS, Scopus and Google Scholar

- Research which is freely available for redistribution 